\title{
Instance Identifier Data Type
}

National Cancer Institute

\section{Source}

National Cancer Institute. Instance Identifier Data Type. NCI Thesaurus. Code C95664.

A data type comprised of an identifier that uniquely characterizes an individual entity. 